\title{
Harnessing the Power of Your Culture for Outstanding Service
}

\author{
Robert Ford and Michael C. Sturman
}

Your company's culture can be one of the strongest forces for ensuring excellent customer service and the resulting financial success, or it can stand in the way of your ever achieving your service and financial goals. Company cultures come in all shapes and sizes, but all cultures are assembled from specific parts, such as language, beliefs, and philosophies. In this chapter, we review the elements of corporate culture, give examples of successful corporate cultures, and point out key ways that you can harness your company's culture for outstanding service.

\section{Culture Defined}

Although you undoubtedly have a solid concept of culture, and your firm may even state your culture for all to see, let's start with the following definition. An organization's culture is a way of behaving, thinking, and acting that is learned and shared by the organization's members. So it is the shared philosophies, ideologies, values, assumptions, beliefs, attitudes, and norms that knit a community together. All of these interrelated qualities reveal a group's agreement, implicit or explicit, on how its members should behave, especially when they approach decisions and problems. You might think of culture as "the way we do things around here." Although cultural inertia can be strong, cultures do change, however gradually, due to both outside influences and internal decisions. A culture both influences its members and in turn is influenced by its members.

We've borrowed examples of corporate culture from such diverse firms as Walt Disney World Resort, Southwest Airlines, Nordstrom's, Ritz-Carlton, Gaylord Palms, and Four Seasons Hotels, among others. If you are a member of one of these organizations, you are well aware of the power of culture. If not, these firms present clear examples of how to instill a culture of successful service that creates financial success, regardless of the business concept or niche.

Before we go deeper into the elements of culture, however, we need to underline where you come in as a corporate leader-regardless of your position or formal level. Successful corporate culture depends on leaders-executives, managers, supervisors, and even line employees - to convey and reinforce the culture as a method of ensuring successful service. The sample companies have one thing 
in common: strong corporate cultures that are driven from the top of the organization and exhibited by all. These cultures were enunciated by a founding visionary and expanded and developed by corporate leaders. Walt Disney began with his vision of "Imagineering"; Herb Kelleher developed a culture for Southwest Airlines that was uncommon for that business; Horst Schultze instilled the concept of "Ladies and gentlemen serving ladies and gentlemen" at Ritz-Carlton; Isadore Sharp created an unrelenting focus on service at Four Seasons; Kemmons Wilson devised a family-oriented culture to match his concept of product consistency for Holiday Inn; and Bill Marriott Sr. and Bill Marriott Jr. developed the customer-oriented culture found at Marriott hotels.

Simply declaring a corporate culture is not enough, of course. You and all other corporate leaders must live that culture. As Isadore Sharp pointed out: "Employees are natural boss watchers. Everything their bosses say and do tells employees their real concerns, their real goals, priorities, and values." ${ }^{1}$ In short, you must consistently act 'within, and, if necessary, enforce your company's culture, if you want your employees to believe in it. Next, let's look at the elements of culture, and then we'll discuss how you can use culture for successful service.

\section{Beliefs, Values, and Norms}

We just defined culture in terms of shared philosophies, ideologies, values, assumptions, beliefs, attitudes, and norms. ${ }^{2}$ Let's take a look at the key elements of culture, beginning at the end of that definition. As a leader in a culture-driven organization, you seek to define the beliefs, values, and norms of the organization through what you do, say, and write, and whom you reward, recognize, and promote.

Beliefs. Beliefs form the ideological core of the culture. A belief is how people in organizations make sense of their relationships with the external world and its influence on the organization. Beliefs define the relationships between causes and effects for the organizational members.

As a simple illustration, if people in an organization believe that the marketplace rewards those organizations that provide good service and punishes those that don't, then the importance of providing good customer service becomes a cultural belief. Culture involves a multitude of beliefs and assumptions about how the environment operates. Most critically, your employees' beliefs reflect how they and your organization will respond to each day's events. The management of an organization that understands the importance of these beliefs will take an active role in defining both the assumptions and the beliefs that those assumptions create. 
Values. Values are preferences for certain behaviors or certain outcomes over others. Values define for members what is right and wrong, preferred and not preferred, desirable behavior and undesirable behavior. Obviously, your company's stated and implicit values can be a strong influence on employee behavior. If management sends a clear signal to all employees that providing good customer service is an important value, then the employees know they should adopt this value and behave accordingly.

Norms. Norms are standards of behavior that define how people are expected to act while part of the organization. Some of your organization's many norms are immediately obvious to both employees and guests, but others require the advice and counsel of veteran employees who have learned these norms over time, especially by what gets rewarded and what doesn't.

Most outstanding hospitality organizations have norms of greeting a guest warmly, smiling, and making eye contact to show interest in the guest. Some use "the 15-foot rule" in which any employee must make positive contact with the guest within this "hospitality zone." Your company might even print service norms like this one on cards and supply them to every employee to serve as the guidelines for service.

Cultural norms in the hospitality industry are strongly defined and shaped by guests who make their expectations plain. Because the hospitality industry's service almost always involves an interaction between employees and guests, guests themselves become potent assistants to the managers in monitoring, reinforcing, and shaping employee behavior. Because guests are involved in "coproduction," your repeat guests are probably aware of your culture. At Disney, for instance, the guest service guidelines are so well established that even the guests often know them. If a ride operator in the Magic Kingdom fails to make eye contact or doesn't smile, a park patron will undoubtedly notice and perhaps remark on the "abnormal" behavior.

Norms of Appearance. In addition to the norms of behavior, most hospitality organizations also have norms of appearance, including standards of personal grooming. Your firm may set norms for hair length, jewelry, fingernails, facial hair, and visible tattoos. These appearance norms are included in your culture because appearances are important in hospitality organizations. Ritz- Carlton employees are "ladies and gentlemen." Disney wants a conventional appearance for its cast of characters to create the realistic illusion inherent in its show. Similarly, employees at the Hard Rock Cafe or Hooters must themselves have a particular appearance (far different from what Disney expects).

Folkways and Mores. Folkways are the customary, habitual ways in which organizational members act or think, without reflecting upon them. Shaking hands (or not shaking hands); addressing 
everyone by first name, or by last name with complimentary title; and wearing or not wearing a tie are folkways. In a restaurant, a folkway might be to roll silverware when there is nothing else to do in the quiet times between crowds.

An organization's mores are folkways that go beyond being polite. These are customary behaviors that must be followed to preserve the organization's efficient operation and survival. Mores require certain acts and forbid others. By indicating what is right and wrong, they form the basis of the organization's code of ethics and accepted behaviors.

\section{Communicating the Culture}

While the substance of culture is a set of assumptions that lead to beliefs, values, and norms, other key elements of culture involve how it is communicated to those inside and outside the organization. These communication elements of culture include laws, language, stories, legends, heroes, symbols, and rituals.

Laws

The laws of an organization are its rules, policies, and regulations-the norms that are so important that they are turned into a code of conduct. Two norms are so important to Disney that they are corporate policies - in effect, laws that carry termination as the penalty for violations. A cast member in costume must not walk in an area where the costume is inappropriate. So, for instance, an employee in the futuristic Tomorrowland outfit cannot appear in Frontierland. Another strict policy is that cast members portraying Disney characters must stay completely in character and cannot be seen out of costume or do anything else that might destroy the Disney fantasy. Indeed, a policy forbids transporting any character costume in a public area unless it is in a black bag that completely covers all its parts so no one will see a favorite fantasy character "in pieces."

\section{Language}

Each organization develops a language of its own as part of its culture. Elements of this language can be incomprehensible to outsiders, as you are well aware if you know any teenagers. The special language helps create a coherent social group, so it is an important vehicle for both communicating the common cultural elements to which the language refers and in reaffirming your employees' identity with their culture. 
Using another example from Disney, this firm uses show business terms for its employees and hiring. Cast members are recruited by casting. This terminology puts everyone together equally as part of the organization (the production), and it reminds people that they are playing "roles" that help make up the Disney "show." This show concept is reinforced by the use of other terms such as on stage to define all situations and areas where cast members are in front of their customers and back stage to define areas the customers cannot see. Thus, cast members constantly think of themselves as participants in an ongoing stage production designed to create a magical fantasy experience. So effective is this training in language that Smith and Eisenberg reported that none of the 35 Disneyland Park employees they interviewed used such typical hospitality terms as uniforms, customers, or amusement park; instead, they referred to costumes, guests, and property. ${ }^{3}$

Stories, Legends, and Heroes

Stories, legends, and heroes transmit culture by communicating proper behaviors. The RitzCarlton is especially noted for the use of many teaching stories. For example, to teach going the extra mile to serve a customer, the story of the New Gold Standard reports the following letter from a guest:

My wife accidentally broke a bottle of makeup that she had brought along and left it in pieces on the counter in the bathroom because she wanted to use as much of it as possible. We came back to the room one day to find a note sitting beside the broken makeup bottle from housekeeping offering to replace the broken bottle they didn't even break. ${ }^{4}$

Focusing on its theme of the "power of personal service," Four Seasons tells the story of an employee who overheard a guest telling his wife how embarrassed he was to be the only one without a black tie at a formal function. The employee asked the man to take a seat in his office, and then quickly took off his own tuxedo and rushed it to laundry. Once the tux was clean, this employee called a seamstress to fit the guest. Not only does this story teach the shared Four Seasons values, but the guest turned out to be the chairman and CEO of a leading consulting organization who subsequently directed all of his company's business (worth millions in food and lodging) to the Four Seasons. The man also took every opportunity to give a testimonial for Four Seasons.

Stories like these give you a way to define and teach what your guests find inspiring and what will cause them to give top evaluations. Indeed, many of the examples we offer in this chapter come from the stories used in employee orientation training. Long-established companies, such as Disney, Darden, and The Ritz-Carlton, have a vast repertoire of stories, but what if your firm is relatively new, 
such as a just-opened hotel? That was the situation facing the Gaylord Palms, a 1,400-room convention hotel located in Orlando. Like the other Gaylord properties (including its flagship, Gaylord Opryland), the property is tightly focused on "extraordinary meetings and conventions" for its guests. To take advantage of the power of stories as a training tool, management created a letter from a fictitious customer to show new employees what the intangible mission of extraordinary meetings means through the customer's eyes. If you haven't already done so, you should encourage your organization to build up its storehouse of stories describing people who did amazing things for your guests, created magical moments, and provided exemplary service.

Symbols

A symbol is a physical object that communicates an unspoken message. At Walt Disney World Resort, Mickey's famous mouse ears are everywhere, including plants grown in mouse-ear shapes, anniversary service pins, and the entrance to Team Disney, which is framed by ears. Mouse ears are subtly hidden everywhere around the property and serve as a constant symbolic reminder of where Disney began and its cultural values.

\section{Rituals}

Rituals are symbolic acts that people perform to gam and maintain membership or identity within an organization. Your company's training program has ritualistic significance because everyone goes through the experience upon entry into the company. Additionally, most hospitality organizations develop elaborate ritual celebrations of service excellence. These can range from a simple event like a departmental pizza party to honor all those receiving positive comments on customer comment cards, to very elaborate Employee of the Year award ceremonies that resemble a major gala.

Gaylord's management, which refers to its employees as STARS, gave extra effort to the development of three rituals that would celebrate and reinforce the culture and its commitment to its employees. ${ }^{5}$ One ritual was designed for celebrating promotions. The supervisor of promoted STARS pedals the promoted person around the premises on a three-wheeled bicycle. Camera-toting paparazzi wave a sign and make a commotion. As the person is pedaled around the hotel's 10 acres, both front of the house and back, everyone can see and celebrate the event. Guests sometimes even join in the parade. A second ritual is a quarterly "All STARS" rally, which publicly celebrates the successes of individual contributors by selecting STARS in the hotel that best represent the resort's values. In the third ritual, at the end of the year, a corporate-wide process selects the best representative of each 
value, and that person is flown to Nashville with their family for a corporate-level celebration. The winners have dinner on the stage of the Grand Ole Opry and get $\$ 1,500$ to give to the charity of their choice.

\section{Teaching the Values}

Although observant guests and employees can infer many elements of your culture, it's still essential to teach your values to new employees and reinforce your values to existing employees. Since everyone brings to a new job the cultural assumptions of past experiences, you must start teaching new cultural values to your employees from day one. Companies known for their strong cultures-like Disney, The Ritz-Carlton, and Four Seasons-earned that reputation by spending considerable time and money on developing their cultures for all entering employees. To socialize its new employees, the Gaylord Palms begins its orientation with two days of training, in which 60 percent of the time is dedicated to teaching culture. Orientation is followed by one to four weeks in the individual departments, where new employees get training in both job skills and more training in the Gaylord culture. This initial orientation is followed by an "orientation reunion" 90 days later to ensure that the employees know their benefits, are comfortable in their job roles, and can see how to apply the flawless service philosophy in their specific departments.

\section{Experiencing Culture}

\section{Barbara Talbott, CEO GlenLarkin Advisors}

Building a global brand to support a global hotel organization takes a diverse mix of skills. Some are learned on-property, while others come from farther afield. Despite distances-doing business in more than 30 countries-and despite their different backgrounds and areas of expertise, the Four Seasons marketing team had proved effective. Business results were on track. Trust and collaboration were evident. But everyone believed that more was possible. The solution that the team devised was to spend 24 hours on-property, in Toronto, together with colleagues from the hotel. The goal of this "retreat" was to take effectiveness and teamwork to another level by experiencing the culture in a more meaningful way.

Think of it as a day of circuit training that began with morning meetings and moved on through key functions around the hotel. In the kitchen, the group assembled fresh asparagus 
bundles for salades composées. Later, they quickly turned a meeting room to make way for a private luncheon. Sales shared an update on their key accounts. The concierge coached them on how to give a good restaurant recommendation. There were no lectures and no real handouts. But at each step there was plenty of patience, encouragement, confidence-and quiet urgency.

Housekeeping staff played a major part, demonstrating how many elements must come together to create the comfortable room and "perfect sleep" that guests expect. This group of marketers knew that the bed and bedding were custom manufactured and that great care had been given to how every ingredient was assembled. They knew that, over time, the process had also been refined to reflect guest comments along with learning from hotel management and staff.

The task was to watch, and occasionally help, with the bed-making process. The guide was an experienced housekeeper who, as she worked, also explained how the standards are kept: "New staff get help from trainers who've been here longer. Then the supervisor inspects some rooms every day. Not just for new staff. Any room might be inspected."

One member of the marketing team then raised her hand.

"How does the supervisor know if the bed's made properly?" she asked. "I understand how the rest can be checked, but the bed is different. Does it have to be unmade, so the supervisor can be certain that it's right?"

"No, that's not necessary," the housekeeper answered. "You see, I would know myself. If the bed wasn't right, then the guest wouldn't sleep as well-and that would not be all right with me."

That night the marketers slept in those well-made beds. The next day, before leaving, the group talked about what they had seen and heard: the many impressions of kindness, skill, and commitment. The woman who'd asked the question shared her story, still deeply impressed by the housekeeper's response.

There are many ways to create and share a service culture. Words are needed but actions convey what words cannot. In the case of this group, actions compressed into a single day accomplished many things. Those who had worked in Four Seasons hotels were reminded how fresh and real the values remained. Those who had never done so gained their own sense of ownership and appreciation for what makes the service possible. Together, they had experienced all of this firsthand, in ways that continue to find expression in their work today. 


\section{Subcultures}

We must note that an overall culture is usually composed of subcultures, particularly in large organizations. The chief points to note about subcultures are that they exist and that you need to ensure that the subculture's beliefs and norms support your company's main culture. One particular subculture split might be full-time employees and part-time employees. The part-timers in particular may not spend enough in your operation to absorb its culture or care enough about the organization and its members to substitute its values for their own. So be on guard and do what you can to ensure that the subcultures are consistent with the core cultural values even if some specific behaviors, beliefs, and norms do vary somewhat from the desired culture. Here's a place where leadership is critical in promoting your company's culture.

\section{National Cultures}

If your company is an international operator, you have seen the effects of cultural differences from one country to another. Disney, for instance, discovered that its EuroDisney (now Disneyland Paris) could not simply transport the entire Disney culture to France and has made necessary adjustments. Seeing this outcome, Four Seasons Hotels took a different approach when it opened its Four Seasons Hotel King George V Paris. It conducted a service quality audit to identify some of the differences between French and North American business culture. Based on these differences, they then altered policy so that it fit with the French culture, rather than assuming the American culture could be forced on employees at the new location.

\section{Harnessing Your Company's Culture}

Now that we have examined the many elements of culture, let's return to your role as a manager of culture. You are the person who shares, emphasizes, and embodies your company's culture. Every chance you get, you should reinforce your company's cultural points. Easily said, but challenging in a hospitality environment. Despite the challenge, though, managing your culture is a crucial task, as culture can play an important strategic role in helping you achieve your company's guest service and financial goals.

One goal set by Gaylord Palms, for example, was to get perfect " $5 \mathrm{~s}$ " on its customer satisfaction measures. From its opening in 2002, its general manager strategically defined a path toward top customer satisfaction, starting with creation of a customer-focused mission and values. His leadership 
team would teach these cultural values and beliefs to all STARS. Gaylord used a variety of communication tools to build trust in and affirm management's commitment to the culture. To emphasize its support of the staff, it uses the term STARS first. This message commitment to the staff was backed up by an "employee guarantee," which gives every employee direct access to top management if the promised employment relationship was not being delivered. The guarantee was created to build trust that management really believed in its "STARS" first cultural value.

The customer satisfaction data collected by the Gaylord Palms confirm the success of this approach. Not only did they achieve a strong showing of " $5 \mathrm{~s}$," but they also gathered every meeting planning award and best place to work award in their market. ${ }^{6}$ When this culture was later implemented in other Gaylord properties, it led to the same results in employee and customer satisfaction and financial performance.

\section{Strategy and Employee Commitment}

Your firm's competitive strategy provides the basis for such critical decisions as how your organization will be structured, what type of service it wants to deliver, what market niche it seeks to fill, what production and service delivery system it will use, who it will hire, and how it will train, reward, promote, and evaluate those people. Since the only way to implement those critical decisions is through employees committed to your mission, you need to use your culture strategically to motivate your employees. We should note here that, as discussed in Chapter 11, money is an important part of this motivation, but many other factors influence hospitality employees' motivation. A strong and focused organizational culture becomes an especially important managerial emphasis in hospitality organizations. The Boulders, a luxury property in Arizona, has the vision statement "Seek opportunities to create memories." This vision is emphasized through the use of coaches, orientation, training, and employee recognition programs. ${ }^{7}$ The culture does not spell out specific actions to take, but emphasizes how the employees should look for opportunities to deliver excellent service.

\section{Culture as a Competitive Advantage}

Your culture can provide significant competitive advantage if it has value to its members, is unique, and cannot be easily copied by others. If an organization has a strong culture that others cannot readily duplicate, it can use that culture to attract both customers and employees. If you want to benchmark other companies' cultures, look for those that have used culture in this way, to develop competitive advantage. ${ }^{8}$ Southwest Airlines is an example of a company that has done this, with its 
"Living the Southwest Way" culture, which espouses both "displaying a Warrior Spirit" (i.e., work hard, desire to be the best, be courageous, display a sense of urgency, persevere, and innovate), and having a "Servant's Heart" (i.e., follow the golden rule, adhere to the basic principles, treat others with respect, put others first, be egalitarian, demonstrate proactive customer service, and embrace the SWA family).Through all of this, the Southwest culture embraces a "Fun-LUVing Attitude" (i.e., have fun, don't take yourself too seriously, maintain perspective (balance), celebrate successes, enjoy your work, and be a passionate team player). ${ }^{9}$ (LUV, of course, is a pun on the Southwest hub, Love Field, and on its stock ticker sign, LUV—a classic example of a cultural in-joke.)

Maintaining Southwest's Culture. Southwest also has engaged its employees to reinforce and teach its culture, as do many other outstanding firms. Southwest Airlines does this with a Culture Committee, whose responsibility was perpetuating the Southwest Spirit. The Culture Committee was created in 1990 "to take the lead in preserving the airline's unique culture." ${ }^{10}$ Originally, it was made up of 38 people, most of whom had 10 or so years at Southwest and embraced Southwest's maverick, caring, irreverent way of doing things. It has since expanded to well over 100 individuals, with representatives from each station and part of the airline. ${ }^{11}$ Committee members have been known to visit stations with equipment and paint in hand to remodel a break room, or surprised maintenance employees with pizza and ice cream. Still others simply show up periodically at various field locations to lend a helping hand.

\section{Management by Culture!}

As you work to strengthen your company's culture, you will discover that your job becomes easier in many ways. A strong, effective culture supplants policies, procedures, and managerial directives by instilling in employees the knowledge of what to do in nearly any situation. Today's thinner hospitality organizations must find ways to delegate more decision-making responsibility and empower their employees, especially their guest-contact employees. Indeed, the more uncertain the task, the more employees must depend on corporate values instead of managerial instructions, formal policies, and established procedures to guide their behavior. ${ }^{12}$ In vague and uncertain situations, you can rely on a strong culture to guide your employees to do the right thing.

\section{Leaders Teach the Culture}

Although we said that strengthening the culture will simplify your job in some ways, you'll still need to constantly teach the culture to your employees-all the time reinforcing your firm's values, 
mores, and laws. Ed Schein, one of the earliest researchers on corporate culture, suggests that the only thing of real importance that leaders do is to create and maintain the organization's culture. ${ }^{13}$ Perhaps that is a bit of hyperbole, but the fact remains that the best leaders personally model their commitment to the service mission, and they do it visibly. They back up slogans with dramatic, sometimes costly actions. To instill values, they stress two-way communications, opening their doors to all employees and using weekly (sometimes daily) workgroup meetings to inform, inspire, and solve service problems. They put values into action by treating employees exactly as they want employees to treat their customers. ${ }^{14}$ They use rituals to recognize and reward the behaviors that the culture values, and they praise the heroes whose actions have reflected worthy cultural values in the stories they tell. Other employees can use these hero stories as models for their own actions.

Schein suggests that leaders can use the following five primary mechanisms to define and strengthen the organization's culture: "(1) what leaders pay attention to, measure, and control; (2) leader reactions to critical incidents and organizational crises; (3) deliberate role modeling, teaching, and coaching by leaders; (4) criteria for allocation of rewards and status; (5) criteria for recruitment, selection, promotion, retirement, and excommunication." ${ }^{15}$

Setting the Example. Bill Marriott Jr. provides a good example of how a leader can help to sustain his company's culture. Large as his company is, he is famous for dropping in at a hotel and chatting with everyone he sees. He has been known to get up early in the morning and wander into the Marriott kitchens to make sure the pancakes are being cooked properly. This intense commitment to personal contact with Marriott employees and visible interest in the details of his operations have become so well known in the Marriott organization that his mere presence on any Marriott property serves as a reminder of the Marriott commitment to service quality. ${ }^{16}$

\section{The Role of a Leader}

Charles A. Conine, SPHR, Cornell 1973

July 1967. In the midst of a summer lunch rush the restaurant's side door swung open and the CEO strode in confidently, smiling and dressed impeccably. He was accompanied by the restaurant's general manager, intent on fulfilling the big boss's wish to "meet and greet" line employees of the ever-expanding enterprise that bore his name. Meanwhile, a young boy working the cook's line concentrated on a different, more urgent task: filling two fryer baskets with French fries to supply hungry guests at the takeout counter. Just then, at the precise 
moment the CEO moved toward the boy, his hand outstretched in greeting, the bottom of the case of French fries the boy held gave way-and 30 pounds of sliced spuds spilled out, coming to rest squarely on the CEO's brightly polished shoes. Unfazed, the CEO laughed and shook the kid's hand as the general manager glowered nearby.

Years later, the "kid" found himself employed as a vice president by the same CEO's eponymous, now worldwide hospitality company. Once again, it was a chance meeting that brought the CEO and the young man together as they stood in a hallway at company headquarters. Yes, the CEO chuckled, he was certain he remembered the infamous French fry moment two decades earlier, laughingly adding, "We didn't hold it against you, did we?"

Two galvanizing moments had two very different impacts. The first, when the young man was only a child, produced raging fear and motivated the boy to pay closer attention to his work. When a second encounter brought the two men together once more, it caused the younger man to further rededicate himself to the CEO's vision of building profits and satisfied employees.

Truly great leaders needn't shout or make splashy headlines to induce motivation; sometimes all that's needed are a few small moments, costing nothing but the leader's time, to galvanize, provoke, and excite an employee's spirit-yielding results that impact both companies and the people who serve them.

By the way, the boy was me. The CEO? J. Willard Marriott Jr.

The vision of deceased leaders also can continue to inform a corporate ${ }^{\wedge}$ culture, as in the case of Kimpton Hotels \& Restaurants, which maintains a culture based on Bill Kimpton's vision. Although Kimpton died in 2001, the culture he created lives on through the organization's new leadership. According to Niki Leondakis, chief operating officer,

One of the things we do at employee orientation is talk to every one of our employees. Once a year, I and one of our senior executives travel around the country on the Kimpton National Tour and bring together all the employees at each hotel. We talk about the culture of care. It means caring for your co-workers, caring for our guests, caring for the environment, our community, our investors. ${ }^{17}$

The clear commitment to the customer-service culture, demonstrated through the actions of those on the top of the organizational chart, sends a strong message to all employees that everyone is 
responsible for maintaining a high-quality customer experience. This same modeling behavior can be seen in the many hotel managers who visibly and consistently stop to pick up small scraps of paper and debris on the floors as they walk through their properties. Employees see and emulate this care and attention to detail.

\section{What We Know About Culture}

We believe that people will judge your strength as a leader by how well you employ your culture as a mechanism to achieve your company's objectives. By concentrating on using the tools and principles we discussed in this chapter, you can ensure a unified message to employees. They will receive- and perform-according to a consistent set of cultural beliefs, values, and norms. Throughout this chapter, we have emphasized that consistency is important to reinforce the culture. The more consistently you use your cultural mechanisms, the more powerfully reinforced the culture will be. Make your messages intentional and explicit. What you get angry or excited about tells everyone what is important. In particular, if you express outrage over a service failure caused by a careless employee, this sends a strong message to all the employees that good service matters. A story is told of how Bill Marriott Sr. fired an employee on the spot for insulting a guest. When this story got around the organization, there was no question in anyone's mind of the guest orientation that Marriott valued.

In closing, here are some principles about organizational culture that seem to hold generally true. For each principle, there are clear reasons why you should pay careful attention to culture in your organization.

- Leaders define the culture (or redefine it, if necessary), teach it, and sustain it. To create and maintain a service-oriented culture, this may be your biggest responsibility.

An organizational culture that emphasizes interpersonal relationships is uniformly more attractive to professionals than a culture that focuses on work tasks. ${ }^{18}$

- Strong cultures are worth building; they can provide employee guidance in uncertain situations where company policies or procedures are unavailable or unwritten. There are thus crucial benefits to having a service-oriented culture, and it is worth your while to find ways to be successful in helping create and sustain such a culture.

- Subcultures 'will form in larger organizations. If you develop and maintain a strong culture, it will increase the likelihood of keeping the subculture consistent with the overall culture values in important areas. 
As a final point, sustaining the culture requires constant attention to the means of communicating culture. You must consistently reinforce and teach the organization's beliefs, values, and norms of behavior to all employees.

\footnotetext{
${ }^{1}$ I. Sharp, Four Seasons: The Story of a Business Philosophy (New York: Penguin Group, 2009): 101.

${ }^{2}$ Definitions in this section are indebted to H. M. Trice and J. M. Beyer, The Cultures of Work Organizations (Englewood Cliffs, NJ: Prentice-Hall, 1993): 33-34.

${ }^{3}$ J. Van Maanen, "The Smile Factory: Work at Disneyland," in P. J. Frost et al., eds. Reframing Organizational Culture (Newbury Park, CA: Sage, 1991): 66.

${ }^{4}$ J. A. Michelli, The New Gold Standard: 5 Leadership Principles for Creating a Legendary Customer Experience Courtesy of the Ritz-Carlton Hotel Company (New York: McGraw-Hill, 2008): 181.

${ }^{5}$ T. E. Deal and M. K. Key, Corporate Celebration (San Francisco: Berrett-Koehler, 1998).

${ }^{6}$ R. C. Ford, C. P. M. Wilderom, and J. Caparella, "Strategically Crafting a Customer-Focused Culture: An Inductive Case Study," Journal of Strategy and Management 1 (2008): 143-167.

${ }^{7}$ C. A. Enz and J. Siguaw, "Best Practices in Service Quality," Cornell Hotel and Restaurant Administration Quarterly 41 (5) (2000): 20-29.

${ }^{8}$ For further information on adapting the culture ideas of other organizations, see J. A. Chatman and K. A. Jehn, "Assessing the Relationship between Industry Characteristics and Organizational Culture: How Different Can You Be?" Academy of Management Journal 37'(3) (1994): 522-553.

${ }^{9}$ www.southwest.com/careers/culture.html (downloaded 9/4/09).

${ }^{10}$ www.southwest.com/about_swa/airborne.html (downloaded 9/7/09).

${ }^{11}$ A. McGee-Cooper, D. Trammell, and G. Looper, "The Power of LUV: An Inside Peek at the Innovative Culture Committee of Southwest Airlines," Reflections: The SoL Journal 9(\) (2008): 49-55.

${ }^{12}$ For more information on this point, see W. H. Davidow and B. Uttal, Total Customer Service (New York: Harper, 1989): 96-97.

${ }^{13}$. E. Schein. Organization Culture and Leadership. (San Francisco: Jossey-Bass, 2004$): 2$.

${ }^{14}$ Davidow and Uttal, 107.

${ }^{15}$ Ibid., 224-225.

${ }^{16}$ H. B. Gregersen and J. S. Black, "J. W. Marriott, Jr., on Growing the Legacy," Academy of Management Executive 16(2) (2002): 33-39.

${ }^{17}$ C. Wolff, "What Makes Kimpton Cool," Lodging Hospitality 11(8) (2008): 42-43.

${ }^{18}$ H. B. Gregersen and J. S. Black, "J. W. Marriott, Jr., on Growing the Legacy," Academy of Management Executive 16(2) (2002): 33-39.
} 